\title{
Internet Prospective Study
}

\author{
Jesús Alvarez-Cedillo*1, Elizabeth Acosta-Gonzaga ${ }^{2}$, Mario Aguilar-Fernández ${ }^{3}$, Patricia \\ Pérez-Romero ${ }^{4}$ \\ 1,2,3 Instituto Politécnico Nacional, Unidad Profesional Interdisciplinaria de Ingeniería \\ y Ciencias Sociales y Administrativas, Av. Té 950 Col. Granjas México, CDMX, México \\ ${ }^{4}$ Instituto Politécnico Nacional, CIDETEC, Av. Juan de Dios Batiz, esquina con Miguel Othón de \\ Mendizábal Edificio CIDETEC, 07738, CDMX, México \\ *Corresponding author, e-mail: jaalvarez@ipn.mx
}

\begin{abstract}
The Internet is currently the largest network of communication worldwide and is where technological advances could be observed. The original creation of the Internet was based on the idea that this network would be formed mainly by multiple independent networks with an arbitrary design. The Internet is the place where all countries communicate and disseminate information in real time, this phenomenon directly affects economies, businesses, and society. This article shows what the future of the Internet is, our research carries out a qualitative prospective analysis on projects and investigations in which the scientific community is currently working, the information is analyzed, and the highlighted topics are shown.
\end{abstract}

Keywords: internet foresight, FI-PPP, FIWARE, FI-CORE, IoT, smart cities, smart homes

\section{Introduction}

The Internet started with the project called ARPANET (Advanced Research Projects Agency Network) in the seventies and by the Advanced Research Projects Agency (ARPA) of the Department of Defense of the United States was founded. ARPANET was a pioneering packet-switched network that would soon include packet satellite networks, terrestrial radio networks and other networks [1-2].

In the 1970s, the traditional method of communication was circuit switching, i.e., networks were interconnected at the circuit level, whose distinctive property was to establish a physical path or circuit and to maintain it throughout the conversation between a point of origin and of destiny. The path could be the single direction (simplex) or two-way (duplex) communication [3].

In contrast, packet-switched networks do not establish a physical path between the source point and the terminal, but the information is transmitted separately by packets [3]. The Transmission Control Protocol (TCP) and the Internet Protocol (IP) are the most widely used data communication protocols; they mostly satisfy the need for global data communication. The success of these rules is due to their characteristics, among which stand out, which are open standards widely available and developed independently of any hardware or operating system. These protocols can unify different hardware and software even if they do not communicate over the Internet [4]. The TCP protocol was ideal for remote session initiation and file transfer applications. However, for some advanced network applications, such as packet voice transmission, it clearly showed that in some cases it could not correct packet loss, and the application should take care of it [2].

In the early years of the creation of the Internet, various applications were proposed, including packet-based voice communication, online chat rooms, social networks and early "worm" programs that showed the concept of agents, and Viruses were also created [2].

Currently, the Internet has more than 3.6 billion users worldwide [5] and is one of the great success stories; its infrastructure supports the economy and social aspects of the planet. As it in the decade of the 70 was designed, the limitations are more and more evident, the reason why it is necessary to evolve the Internet or to change it, initiating a new project. This work shows the future of the Internet, a future not too distant, with a real and not futuristic vision.

Received July 12, 2017; Revised August 18, 2017; Accepted August 31, 2017 


\section{Current Internet}

The initial goal of the creation of the Internet was academic, was used to share specialized information and research. Today the Internet is formed by a large number of services, integrating the most innovative technologies for data processing, video, and sound. The standard data transfer rates are measured in millions of bits per second, i.e., gigabits per second $(\mathrm{GB} / \mathrm{s})$ and millions of pixel resolutions, to meet the needs of the new entertainment markets, Business and telecommunications.

According to [6-7] normal online activities in the world are sending and receiving emails, accessing information about goods and services online, reading news, newspapers, online magazines, e-banking, e-government, online purchases.

In Europe, in the year 2016, the statistical findings [8] mention that a vast majority of people use the Internet for everyday life, education, work and participation in society, as it allows them to access information and services At any time from anywhere.

Given its main feature where it is possible to have a significant amount of information on the Internet and can be accessed almost instantaneously. It can cause more and more users to look for information online and lose interest in reading a book Traditional way, which could even cause them to find traditional or classroom education in a boring and monotonous manner. It is common to use digital media for teaching; this allows to modify traditional school practices such as visits to museums or libraries [6].

\section{Research Method}

Qualitative research is defined as any research that generates results and discoveries in which statistical procedures and other means of quantification are not used "[9].

Qualitative analysis refers to rational and non-mathematical reinterpretation for the purpose of discovering keywords or concepts and relationships in raw data and then organizing them into a theoretical framework "[9]. These qualitative methods were used in particular substantive areas on which is known little or much whit the goal to obtain new knowledge [10].

In [9] there are three main components in qualitative research:

a. The data, which may come from different sources, such as interviews, observations, documents, records, and films.

b. The procedures used to interpret and organize the data, such as:

1) Conceptualize and

2) Reduce data,

3) Elaborate categories, regarding their properties and dimensions,

4) Relate the data using a series of propositional sentences, the previous four are known as encoding.

c. Written and verbal reports can be presented as articles in scientific journals, in talks (for example in conferences), or as books.

According to the purpose of this study, the methodology used for data analysis is the grounded theory proposed by Glaser and Strauss [11] and described in [12], as seen in Figure 1. 


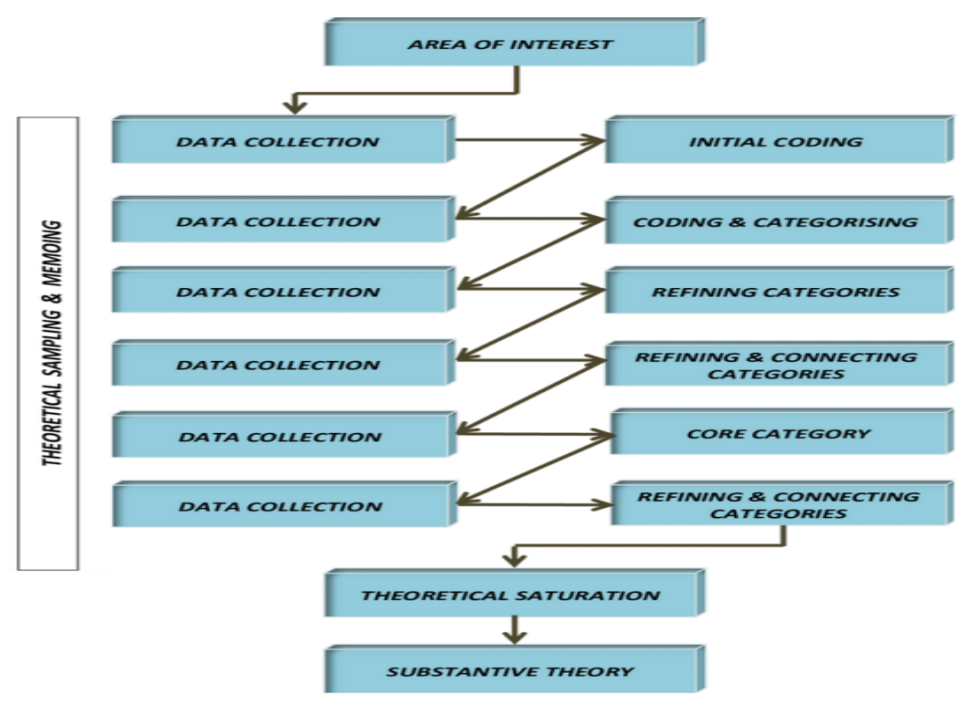

Figure 1. Grounded theory proposed by Glaser and Strauss [11]

In [10], the fundamental theory is a research method in which theory arises from systematically collected data. It does not begin with a preconceived theory, but of the date of the approach so that it resembles reality. Since the purpose of the authors [10] was to create new ways of understanding reality and to express them theoretically, the methods would help build theories. Given the above, fundamental theory is the appropriate method for this study.

We analyzed 2000 scientific articles of international arbitration with the subject of Internet of the future. To perform the data analysis and coding, we used the software for the qualitative analysis NVivo 10 [13]. After performing the data analysis, results were obtained in which the most relevant studies were identified in the subject under investigation, to detect trends.

To elaborate the data analysis, NVivo 10 stores the information in nodes, which are structured in hierarchies or the trees creating topologies. According to the methodology used, we seek to find the elements that form the keywords or properties and with these create the categories.

Also, NVivo 10 uses the constant comparison technique, that is, a measure that encoding is generated, the information found in a text is continuously compared to other coded documents. The categories and properties that emerge from the analysis are combined with the fundamental concepts being sought, it is said, about the theory that is emerging. From the main keywords, it is possible to look for more data to strengthen the original theory.

NVivo 10 also shows when the theoretical saturation has been reached, that is, the saturation of the elements and categories that are being analyzed. It this allows you to focus the search on the full parts and look for documents that have not yet reached that level. According to the data introduced for this study the frequency of the words is shown in Figure 2.

As can be seen in the analysis of the frequency, the words represented in a cloud show the category of primary technologies that has the most impact at this moment and therefore, will also have effects in the future.

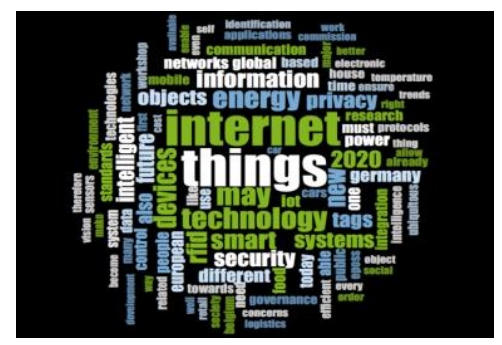

Figure 2. Cloud of words generated with NVivo 10 


\section{Results and Analysis}

According to the results obtained and represented in the word cloud of Figure 3 . Using the data obtained it is possible to make an estimate showing the future-oriented research topics of the Internet as illustrated in Figure 4. The FI-PPP was proposed by the European Commission on May 3, 2011. This research program includes several projects to place Europe At the top of the Internet of the future around the world.

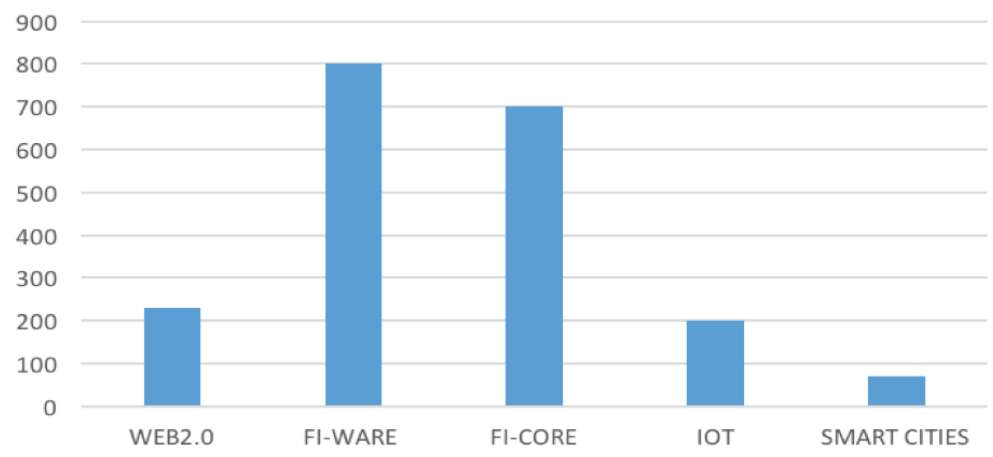

Figure 3. Technologies most relevant to the future of the internet

The FI-PPP program focuses on key areas such as energy, health, and media content. This community develops standard technological components of Internet of the future (called Generic Enablers) that are reusable, open and interoperable with the evolution of infrastructures and technologies [14].

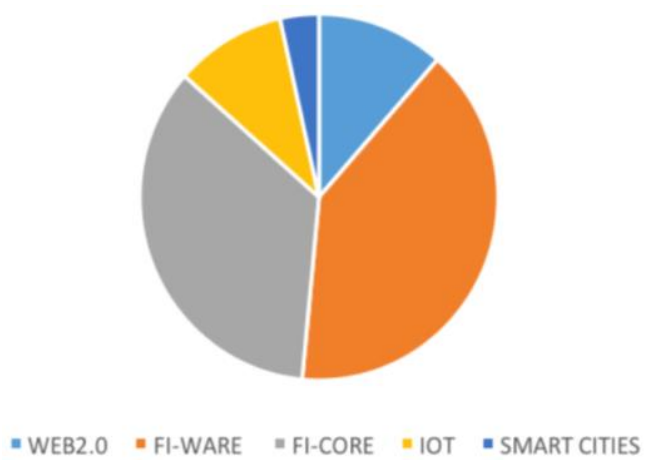

Figure 4. Central projects and technological trends on the internet of the future

The key FI-PPP research project is FI-WARE whose aim is to promote the overall competitiveness of the EU economy by establishing an innovative infrastructure. This project will include key deliverables as an open architecture and a reference implementation of a new service infrastructure, based on generic and reusable building blocks. The design will support emerging (FI) services [15]. FI-WARE is an open middleware platform developed between 2011 and 2014 as a platform for the implementation of new applications and new services related to the Internet of Things, Sensor Networks, Open Data and Intelligent Cities [16].

The results show that the FI-Core project represents $75 \%$ of current research on the future of the Internet. The objective of the FI-Core is to continue the investigation of the FIWARE project that ended in 2016. The percentage of the development of these technologies is shown in Figure 5.

This project will support economic, social and environmental demands that will have the participation of specific projects such as: 
a. Smart Utility. FINESCE (Intelligent Internet Utility Services of the Future-[17].

b. Future business collaboration networks on the Internet in agri-food, transport, and logistics.

c. Investigation of social and technological alignment. Research of the Social and Technological Alignment on Internet of the Future (FI-STAR), this project seeks to satisfy the requirements of the global health industry taking advantage of FI-PPP results.

d. Internet technologies for manufacturing industries.

e. Development of Internet media for large-scale experimentation.

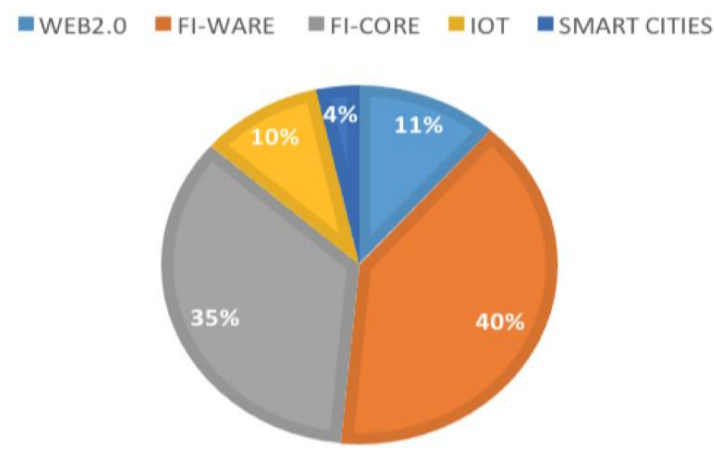

Figure 5. FI-PPP Trends

The race to reach the intelligence of cities has begun. Smart Cities will use ICTs to a large extent, based on their infrastructure and the creation of services. These services are more interactive and efficient, based on the cooperation and awareness of Internet citizens. The Smart Cities as well as spaces committed to their environment and ecology. With this respect for the environment, history and its culture. This interconnected digital system will become a digital platform to optimize and maximize the economy and well-being in society. The society will be constituted with sustainable development. Figure 6 give information about investigation of FI-PPP program trends.

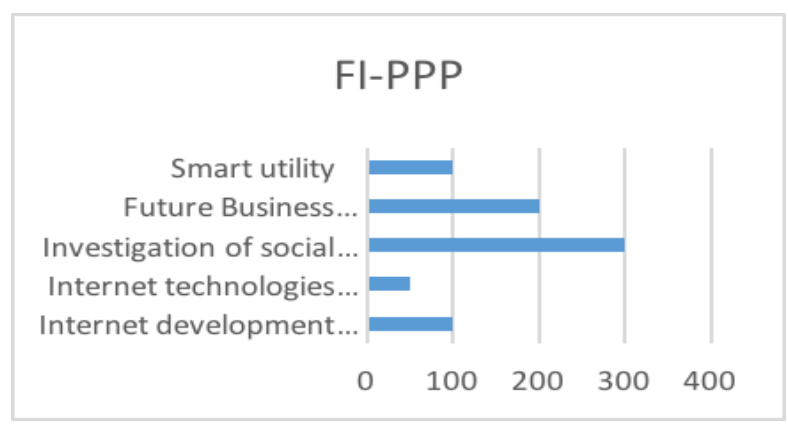

Figure 6. Investigation of FI-PPP program trends

\section{Conclusion}

However, current research shows an uncertain future in geospatial data and processing, on the contrary, research focuses on smart cities. The FI-WARE platform will accelerate the supply of raw materials and the development of technology in small and mediumsized organizations.

It also contributes to the growth and expansion of enterprises through ICT. The real value and success of FI-WARE implementation depend on its ability to provide the only functional and intuitive activators that connect to particular area-of-use enablers. Border 
research topics focus on the various phases of FI-PPP, the creation of sustainable ecosystems based on IT, the consolidation of business and value chains.

\section{Acknowledgments}

Our research team thanks the Instituto Politécnico Nacional y a la Secretaría de Investigación y Posgrado for the support received for the development of investigation, MEXICO, CDMX.

\section{References}

[1] Lievrouw LA. Handbook of New Media: Student Edition. 2006. (p. 253) SAGE, 475 pages. ISBN 1412918731.

[2] Hafner, Katie. Where Wizards Stay Up Late: The Origins of the Internet. Simon \& Schuster. 1988. ISBN 0684832674.

[3] Herrera PE. Introducción a las Telecomunicaciones Moderna. Serie Electrotecnia. Colección de Textos Politécnicos. Ed. Noriega Limusa. 1998. ISBN 968185506X.

[4] Chapman DB, Zwicky ED. Construya Firewalls para Internet. Ed. Mc Graw Hill. 1997. ISBN 1565921240.

[5] Internet Live Stats. 2017 Tomado de: http://www.internetlivestats.com/

[6] Méndez M. Primera Revista Electrónica en América Latina Especializada en Comunicación. 2005. Tomado de: http://www.razonypalabra.org.mx/anteriores/n43/mmendez.html

[7] OECD. org., 2017. Tomado de: http://www.oecd.org

[8] European Commission. Eurostat. 2017. Tomado de: http://ec.europa.eu/eurostat/statisticsexplained/index.php/Main_Page

[9] Strauss A, Cordin J. Bases de la Investigación Cualitativa. Técnicas y Procedimientos para Desarrollar la Teoría Fundamentada. SAGE Publicaciones Inc. Edición en Español. Editorial Universidad de Antoquia, Colombia. 2002. ISBN 958-655-623-9.

[10] Stern PN. Grounded Theory Methodology: Its Uses and Processes. 1980. doi:10.1111/j.15475069.1980.tb01455.x

[11] Glaser B. y Strauss A. The discovery of grounded theory. Chicago: Aldine Press. 1967.

[12] Carrero V. Análisis Cualitativo de Datos: Aplicación de la Teoría Fundamentada (Grounded Theory) en el ámbito de la Innovación Organizacional. Tesis Doctoral. Universidad Jaume I (Castellón). 1998.

[13] Deland Bengt y Mc Dougall A. Nvivo 10 Essentials: Your Guide to the world's Most Powerful Qualitative Data Analysis Software. Stallarholmen: Form \& Kunskap AB. 2013.

[14] Rwthaachen University. 2017. Tomado de: http://www.acs.eonerc.rwth-aachen.de

[15] Fiware. 2017. Tomado de: https://www.fi-ware.eu.

[16] RedIRIS. Red Académica y de Investigación Nacional, España. 2017. Tomado de: https://www.rediris.es/proyectos/Fi-core/ 